\title{
Emergence of Raoultella ornithinolytica isolated from chicken products in Alexandria, Egypt
}

\author{
Sara M. El-Shannat ${ }^{1}$, Ashraf A. Abd El-Tawab² ${ }^{\text {(D) }}$ and Wafaa M. M. Hassan³
}

1. Department of Microbiology, Animal Health Research Institute, Marsa Matruh, Egypt; 2. Department of Bacteriology, Immunology, and Mycology, Faculty of Veterinary Medicine, Benha University, Banha, Egypt; 3. The Reference Laboratory for Quality Control on Poultry Production, Animal Health Research Institute, Dokki, Giza, Egypt.

Corresponding author: Sara M. El-Shannat, e-mail: saramvet@yahoo.com

Co-authors: AAAE: ashrafabdeltwab@yahoo.com,WMMH: fooaaa@live.com

Received: 04-03-2020, Accepted: 04-06-2020, Published online: 29-07-2020

doi: www.doi.org/10.14202/vetworld.2020.1473-1479 How to cite this article: El-Shannat SM, El-Tawab AAA, Hassan WMM (2020) Emergence of Raoultella ornithinolytica isolated from chicken products in Alexandria, Egypt, Veterinary World, 13(7): 1473-1479.

\begin{abstract}
Background and Aim: Raoultella ornithinolytica is one of the emerging gram-negative bacteria, which associated with foodborne illness. Researches affirmed that distinguish between R. ornithinolytica and Klebsiella oxytoca are difficult, as they are phylogenetic related. The evolution of multidrug resistance of Raoultella strains gained more concern for recognition of the pathogen which supports in controlling the disease and minify its threat. This study sought to find a reliable tool for the identification of Raoultella ornithinolytica, isolated from chicken product samples, and assessed the resistance profile of $R$. ornithinolytica using antibiogram sensitivity tests.
\end{abstract}

Materials and Methods: Forty samples of chicken products were collected between January and September 2019 from different markets in Alexandria Governorate, Egypt. The products included nuggets, strips, burgers, luncheon meats, pane, frankfurters, and minced chicken meat. The samples were transferred to the Reference Laboratory. The samples were subjected to isolation, biochemical reaction testing, phenotypic system analytical profile index (API) E20, and a detection of antimicrobial susceptibility test. Phenotypic identification was confirmed through matrix-assisted laser-desorption ionization time-of-flight mass spectrometry (MALDI-TOF MS).

Results: Thirty-three bacterial isolates $(82.50 \%)$ out of 40 samples were isolated into pure cultures from the chicken samples. Three isolates $(9.09 \%)$ were positive for R. ornithinolytica, while 30 isolates $(90.91 \%)$ exhibited growth characters for different pathogens (Escherichia coli, Enterobacter aerogenes, Proteus vulgaris, R. ornithinolytica, and Klebsiella pneumoniae). The isolates of $R$. ornithinolytica were resistant to five types of antibiotics and sensitive to two types of antibiotics.

Conclusion: This study reported the first case of $R$. ornithinolytica found in chicken products in Egypt. Phenotypic system API 20E and MALDI-TOF MS were found to be reliable tools for confirming the diagnosis of $R$. ornithinolytica. As it provides rapid identification with high sensitivity and specificity for $R$. ornithinolytica, which often do not require a molecular procedure for confirmation.

Keywords: analytical profile index 20E, matrix-assisted laser-desorption ionization time-of-flight mass spectrometry, phenotypic system, Raoultella ornithinolytica.

\section{Introduction}

Raoultella ornithinolytica is recognized as histamine-producing Gram-negative bacteria, which usually inhabits aquatic environments such as saturated soil, water systems, and fish [1-6]. These bacteria belong to Enterobacteriaceae family, with distinctive biochemical characteristics that can assist with their discrimination from other phenotypically related species [2,7-11]. It has low nutritional demands and has the ability to survive when food is scarce. Moreover, the growth temperature required is remarkably variable from $4^{\circ} \mathrm{C}$ to $40^{\circ} \mathrm{C}$ [1]. In the

Copyright: El-Shannat, et al. Open Access. This article is distributed under the terms of the Creative Commons Attribution 4.0 International License (http://creativecommons.org/licenses/by/4.0/), which permits unrestricted use, distribution, and reproduction in any medium, provided you give appropriate credit to the original author(s) and the source, provide a link to the Creative Commons license, and indicate if changes were made. The Creative Commons Public Domain Dedication waiver (http://creativecommons.org/ publicdomain/zero/1.0/) applies to the data made available in this article, unless otherwise stated. past, $R$. ornithinolytica was classified as a member of Klebsiella genus and reclassified in 2001 as a new genus Raoultella, based on the sequencing of the $16 \mathrm{~S}$ rRNA and the rpoB gene $[1,12]$.

The use of a standard classical approach is considered a useful tool in the identification of $R$. ornithinolytica $[13,14]$. However, matrix-assisted laser-desorption ionization time-of-flight mass spectrometry (MALDI-TOF MS) and sequence analysis are more highly regarded as they offer the potential for extraordinary insight into pathogens [15].

This study sought to find a reliable tool for the identification of $R$. ornithinolytica, isolated from chicken product samples, and then assessed the resistance profile of $R$. ornithinolytica using antibiogram sensitivity tests.

\section{Materials and Methods}

\section{Ethical approval}

No ethical approval was needed to perform this study. However, the samples were treated according to the national and international criteria. 


\section{Study duration, location, and data collection}

This study took place from January 2019 to September 2019. Forty samples of chicken products were collected from different markets located in or near the center of Alexandria city. The products included nuggets, strips, burgers, luncheon meats, pane, frankfurters, and minced chicken meat. Samples were transported on ice to the Reference Laboratory for Quality Control on Poultry Production, Animal Health Research Institute, Dokki, Giza, Egypt. These samples were sealed in sterile bags and stored at $-86^{\circ} \mathrm{C}$ until testing.

\section{Bacteriological examination of $\boldsymbol{R}$. ornithinolytica}

The samples were pretreated according to a method described previously [16]; briefly, samples were thawed at room temperature, macerated into small pieces using sterile blades, and homogenized using a sterile mortar and pestle. The samples were incubated under aerobic conditions using pre-enrichment (buffered peptone water) at $37^{\circ} \mathrm{C}$ for $24 \mathrm{~h}$ (HiMedia ${ }^{\circledR}$, India). Twenty-five grams of the chicken product sample were pre-enriched into $225 \mathrm{ml}$ buffered peptone water. Then, $0.1 \mathrm{ml}$ and $1 \mathrm{ml}$ of pre-enriched aliquots were transferred into $10 \mathrm{ml}$ Rappaport and Vassiliadis broth for the enrichment and then incubated at $42^{\circ} \mathrm{C}$ for $24 \mathrm{~h}$ (HiMedia ${ }^{\circledR}$, India). The enriched aliquot samples were seeded onto MacConkey and Xylose Lysine Deoxycholate agar (XLD) and incubated at $37^{\circ} \mathrm{C}$ for $24-48 \mathrm{~h}$ to observe colonial growth (HiMedia $^{\circledR}$, India) [17].

\section{Recommended biochemical tests panel for the iden- tification of $R$. ornithinolytica}

The four biochemical tests utilized are illustrated in Table-1 to provide an example of the test variability that occurs using the standard laboratory methods for each test since complete standardization of these biochemical methods has not yet been fully elucidated. Thus, some reports may not provide sufficient data $[7,8,16]$.

\section{Identification using a phenotypic system analytical profile index (API) 20E strips}

Phenotypic system API 20E strips are considered a well-established method for accurate identification, this method depends on the standardized extensive databases [18], the selected isolates and reference strains were then evaluated using a (identification of products) testing kit API 20E (bioMérieux) to minimize the misidentified results of $R$. ornithinolytica strains with Klebsiella oxytoca using a conventional laboratory technique. Preparation procedures occurred based on the manufacturer's recommendation protocol, and the results were analyzed using the API 20E WEB ${ }^{\mathrm{TM}}$ service.

\section{Identification of $R$. ornithinolytica by MALDI-TOF MS} fingerprinting

MALDI-TOF MS fingerprinting (Brüker Daltonik, GmbH, Bremen, Germany; Biotyper 3.0 database) was performed according to the following steps. The samples were prepared based on the manufacturer's guidelines for the identification of Gram-negative bacteria using a formic acid method; the fresh isolates were inoculated into spots on the target plate. Then, $1 \mu 1$ of $70 \%$ formic acid was placed in the microbial spot and left to dry at room temperature. Thereafter, $1 \mu \mathrm{l}$ of MALDI matrix solution was added (saturated $\alpha$-cyano-4-hydroxycinnamic acid in $50 \%$ acetonitrile and $2.5 \%$ trifluoroacetic acid) [19]. Data analysis of MALDI-TOF MS required a fingerprint comparison with a database of reference spectra according to the manufacturer's recommendations through the use of various algorithms.

\section{Antibiotic susceptibility testing}

$R$. ornithinolytica isolates were subjected to antibiotic susceptibility tests according to methods described and interpreted by Clinical and Laboratory Standards Institute (CLSI), 2018. The diffusion disks used in this study were obtained (Oxoid, U.K) as standard reference disks with known potency for laboratory use including flucloxacillin (FLX) $5 \mu \mathrm{g}$; nalidixic acid (NA) $30 \mu \mathrm{g}$; ciprofloxacin (CIP) $5 \mu \mathrm{g}$; oxytetracycline (OTC) $30 \mu \mathrm{g}$; tetracycline (TE) $30 \mu \mathrm{g}$; amikacin (AMK) $30 \mu \mathrm{g}$; streptomycin (S) $10 \mu \mathrm{g}$; erythromycin (ERY) $15 \mu \mathrm{g}$; bacitracin (BAC) $10 \mu \mathrm{g}$; colistin (CS) $10 \mu \mathrm{g}$; chloramphenicol (C) $30 \mu \mathrm{g}$; amoxicillin (AMX) $25 \mu \mathrm{g}$; AMX with clavulanic acid (AMC) $30 \mu \mathrm{g}$; ampicillin (AMP) $10 \mu \mathrm{g}$; and penicillin (P) 10 IU. All $R$. ornithinolytica isolates were subjected to a disk diffusion test. A suspension of each isolate was created with turbidity at $0.5 \mathrm{McF}$ arland standard and then plated onto Mueller-Hinton agar plates (about $25-30 \mathrm{ml}$ per $90 \mathrm{~mm}$ plate, the depth of the medium was $4 \mathrm{~mm}$ ) http://www.uphs.upenn.edu/bugdrug/antibiotic manual/bk.html. Antibiotic sensitivity disks were applied to each plate, and the plates were incubated at $37^{\circ} \mathrm{C}$ for $24 \mathrm{~h}$. Then, the zones of inhibition were measured.

The antibiotic susceptibilities of $R$. ornithinolytica isolates were also determined and interpreted in accordance with CLSI, 2018. Briefly, the samples were subjected to 15 distinct antibiotics (FLX, NA, CIP, OTC, TE, AMK, S, ERY, BAC, CS, C, AMX,

Table-1: Biochemical identification for $R$. ornithinolytica.

\begin{tabular}{|c|c|c|c|c|c|c|c|c|c|}
\hline \multirow[t]{2}{*}{ Sample no. } & \multirow[t]{2}{*}{ Urease } & \multirow[t]{2}{*}{ Oxidase } & \multicolumn{3}{|c|}{ T.S.I } & \multicolumn{4}{|c|}{ L.I.A } \\
\hline & & & Butt/G & Slant & $\mathrm{H}_{2} \mathrm{~S}$ & Slant & Butt & $\mathbf{G}$ & $\mathrm{H}_{2} \mathrm{~S}$ \\
\hline 16 & weak +ve & $-v e$ & $A G$ & $A$ & -ve & $\mathrm{K}^{(\mathrm{P})}$ & $A$ & $-v e$ & $-v e$ \\
\hline 28 & + ve & $-v e$ & $A G$ & $A$ & +ve (black PPt) & $K^{(P)}$ & $A$ & $-v e$ & $-v e$ \\
\hline 40 & + ve & $-v e$ & $A G$ & $A$ & +ve (black PPt) & $K^{(P)}$ & $A$ & $-v e$ & $-v e$ \\
\hline
\end{tabular}

$\mathrm{P}$ (remain purple or the original color), $\mathrm{A}$ (acid), $\mathrm{K}$ (alkaline), and $\mathrm{G}$ (gas). $R$. ornithinolytica=Raoultella ornithinolytica 
AMC, AMP, and P) (Table-2), at a minimum inhibitory concentration and the breakpoint was $5 \mu \mathrm{g}, 30 \mu \mathrm{g}$, $5 \mu \mathrm{g}, 30 \mu \mathrm{g}, 30 \mu \mathrm{g}, 30 \mu \mathrm{g}, 10 \mu \mathrm{g}, 15 \mu \mathrm{g}, 10 \mu \mathrm{g}, 10 \mu \mathrm{g}$, $30 \mu \mathrm{g}, 25 \mu \mathrm{g}, 30 \mu \mathrm{g}, 10 \mu \mathrm{g}$, and $10 \mathrm{IU}$, respectively (Table-2). Antibiotic sensitivity disks were applied to each prepared plate and the plates were incubated at $37^{\circ} \mathrm{C}$ for $24 \mathrm{~h}$. Then, the zones of inhibition were measured.

\section{Results}

Forty samples of chicken products were subjected to conventional identification. Data illustrated in Table-3 and Figure-1 show the results of sample cultivation on XLD, from the different locations in Alexandria Governorate, Egypt. As shown in Table-3, 33 bacteria were isolated and grown into pure cultures from the chicken product samples. The isolated bacteria consisted of $12.1 \%$ (4/33 isolates) Escherichia coli, 6.0\% (2/33 isolates) Klebsiella aerogenes, 3.0\% (1/33 isolates) Proteus vulgaris, 9.0\% (3/33 isolates) $R$. ornithinolytica, and $69.6 \%$ (23/33 isolates) K. pneumoniae.

Table-1 and Figure-2 refer to the results of the individual biochemical reactions (oxidase, Triple Sugar Iron Agar (TSI), Lysine Iron Agar (LIA), and urease) for the expected positive $R$. ornithinolytica isolates, which were then identified as $R$. ornithinolytica by use of an API 20E test. The phenotypic system API 20E confirmed that the three pre-identified samples had proved to be $R$. ornithinolytica based on their positive results for ornithine decarboxylase, ODC+, which is the primary identification test that distinguishes between $R$. ornithinolytica and $K$. oxytoca (Figure-3). Moreover, the three ODC+ samples were subjected to MALDI-TOF MS fingerprinting as a confirmation method for the results obtained by API 20E. MALDI-TOF MS verified the diagnosis of $R$. ornithinolytica. The obtained spectra were compared with a Biotyper database, which revealed that all three samples that were pre-identified using conventional techniques were $100 \%$ correctly identified as $R$. ornithinolytica, with a score value $<2.00$. These results demonstrated that the most effective methods used for the identification of $R$. ornithinolytica were the phenotypic system API 20E combined with MALDI-TOF MS.

The three $R$. ornithinolytica samples were subjected to antibiotic susceptibility tests to evaluate their resistance profiles using antibiotic disks (Oxoid,

Table-2: Result of disk susceptibility determinations for $R$. ornithinolytica samples.

\begin{tabular}{|c|c|c|c|c|c|c|c|c|}
\hline \multirow[t]{2}{*}{ No. } & \multirow{2}{*}{\multicolumn{2}{|c|}{ Antibiotics Conc./MG }} & \multicolumn{2}{|c|}{ Sample 16} & \multicolumn{2}{|c|}{ Sample 28} & \multicolumn{2}{|c|}{ Sample 40} \\
\hline & & & $\begin{array}{l}\text { Zone } \\
\text { diam. } \\
\text { (mm) }\end{array}$ & Interpretation & $\begin{array}{l}\text { Zone } \\
\text { diam. } \\
\text { (mm) }\end{array}$ & Interpretation & $\begin{array}{l}\text { Zone } \\
\text { diam. } \\
(\mathrm{mm})\end{array}$ & Interpretation \\
\hline 1 & $\mathrm{FLX}$ & $5 \mu g$ & 6 & $\mathrm{R}$ & 6 & $\mathrm{R}$ & 6 & $\mathrm{R}$ \\
\hline 2 & NA & $30 \mu \mathrm{g}$ & 25 & $\mathrm{~S}$ & 16 & I & 20 & $\mathrm{~S}$ \\
\hline 3 & CIP & $5 \mu g$ & 30 & $\mathrm{~S}$ & 22 & $\mathrm{~S}$ & 20 & I \\
\hline 4 & OTC & $30 \mu \mathrm{g}$ & 20 & $\mathrm{~S}$ & 6 & $\mathrm{R}$ & 6 & $\mathrm{R}$ \\
\hline 5 & $\mathrm{TE}$ & $30 \mu \mathrm{g}$ & 21 & $\mathrm{~S}$ & 6 & $\mathrm{R}$ & 6 & $\mathrm{R}$ \\
\hline 6 & AMK & $30 \mu \mathrm{g}$ & 19 & $\mathrm{~S}$ & 18 & $\mathrm{~S}$ & 16 & I \\
\hline 7 & $\mathrm{~S}$ & $10 \mu \mathrm{g}$ & 16 & $\mathrm{~S}$ & 6 & $\mathrm{R}$ & 6 & $\mathrm{R}$ \\
\hline 8 & ERY & $15 \mu \mathrm{g}$ & 6 & $\mathrm{R}$ & 6 & $\mathrm{R}$ & 6 & $\mathrm{R}$ \\
\hline 9 & BAC & $10 \mu \mathrm{g}$ & 6 & $\mathrm{R}$ & 6 & $\mathrm{R}$ & 6 & $\mathrm{R}$ \\
\hline 10 & $\mathrm{CS}$ & $10 \mu \mathrm{g}$ & 13 & $\mathrm{~S}$ & 12 & $\mathrm{~S}$ & 12 & $\mathrm{~S}$ \\
\hline 11 & C & $30 \mu \mathrm{g}$ & 26 & $\mathrm{~S}$ & 25 & $S$ & 26 & $S$ \\
\hline 12 & AMX & $25 \mu \mathrm{g}$ & 16 & I & 6 & $\mathrm{R}$ & 6 & $\mathrm{R}$ \\
\hline 13 & AMC & $30 \mu \mathrm{g}$ & 11 & $\mathrm{R}$ & 6 & $\mathrm{R}$ & 10 & $\mathrm{R}$ \\
\hline 14 & AMP & $10 \mu \mathrm{g}$ & 13 & $\mathrm{I}$ & 6 & $\mathrm{R}$ & 6 & $\mathrm{R}$ \\
\hline 15 & $\mathrm{P}$ & $10 \mathrm{IU}$ & 6 & $\mathrm{R}$ & 6 & $\mathrm{R}$ & 6 & $\mathrm{R}$ \\
\hline
\end{tabular}

FLX=Flucloxacillin, NA=Nalidixic acid, CIP=Ciprofloxacin, OTC=Oxytetracycline, TE=Tetracycline, AMK=Amikacin, $\mathrm{S}=$ Streptomycin, $\mathrm{ERY}=$ Erythromycin, $\mathrm{BAC}=$ Bacitracin, $\mathrm{CS}=$ Colistin, $\mathrm{C}=$ Chloramphenicol, $\mathrm{AMX}=$ Amoxicillin, $\mathrm{AMC}=$ Amoxicillin with clavulanic acid, $\mathrm{AMP}=$ Ampicillin, and $\mathrm{P}=$ Penicillin. $\mathrm{R}=$ Resistance, $\mathrm{I}=$ Intermediate, and $\mathrm{S}=$ Sensitive
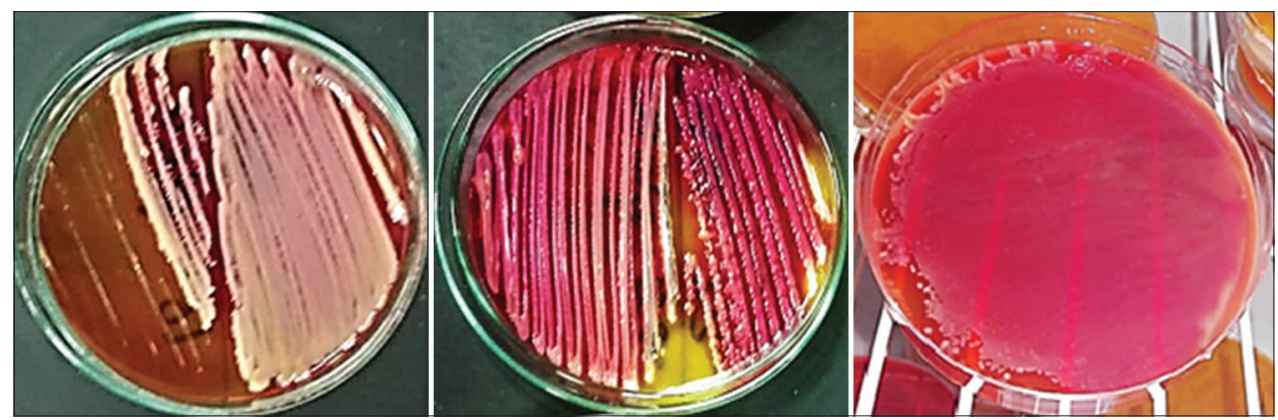

Figure-1: Growth of Raoultella ornithinolytica colonies on XLD agar. 
Table-3: Results of samples cultivation on Xylose Lysine Deoxycholate agar (XLD).

\begin{tabular}{|c|c|c|c|}
\hline Sample no. & Collection area & Source of sample & Result of cultivation on XLD \\
\hline 1 & Borg El Arab & Plain chicken luncheon & + ve \\
\hline 2 & Ras at-Tin & Nuggets & $+\mathrm{ve}$ \\
\hline 3 & Loran & Strips & + ve \\
\hline 4 & Al Anfoshy & Spicy chicken pane & + ve \\
\hline 5 & Ras at-Tin & Chicken burger & + ve \\
\hline $6 * *$ & Flemeg & Chicken burger & $-v e$ \\
\hline $7 * *$ & Ras El-tin & Crunchy spicy chicken pane & $-v e$ \\
\hline 8 & Elanfoshy & Spicy chicken pane & + ve \\
\hline $9 * *$ & Ras at-Tin & Chicken burger & - ve \\
\hline 10 & Kamp Shizar & Chicken burger & + ve \\
\hline 11 & Borg El Arab & Chicken luncheon & + ve \\
\hline 12 & El Raml & Chicken luncheon & + ve \\
\hline $13 * *$ & Al Ibrahimeyya & Crunchy spicy chicken pane & $-v e$ \\
\hline 14 & North coast & Chicken luncheon with olive & + ve \\
\hline 15 & North coast & Chicken luncheon with olive & + ve \\
\hline $16^{*}$ & Borg EL Arab & Plain chicken luncheon & + ve \\
\hline 17 & Al-Ibrahimiyyah & Chicken fingers & + ve \\
\hline 18 & El Ras El Souda & Chicken fingers & $+\mathrm{ve}$ \\
\hline 19 & El Seyouf & Chicken frankfurter & + ve \\
\hline 20 & El Ras el Souda & Chicken frankfurter & + ve \\
\hline 21 & Sidi Bishr & Chicken frankfurter & + ve \\
\hline 22 & Sidi Beshr & Chicken burger & + ve \\
\hline 23 & Roshdy & Chicken burger & + ve \\
\hline 24 & El Seyouf & Chicken burger & + ve \\
\hline $25 * *$ & El Mandara & Chicken fingers & - ve \\
\hline 26 & Gleem & Chicken fingers & + ve \\
\hline $27 * *$ & Smouha & Nuggets & - ve \\
\hline $28 *$ & El Seyouf & Nuggets & + ve \\
\hline 29 & El Shatbi & Smoked chicken luncheon & + ve \\
\hline 30 & El Asafra & Chicken luncheon with olive & + ve \\
\hline 31 & El Mandara & Plain chicken luncheon & + ve \\
\hline 32 & Stanley & Plain chicken luncheon & + ve \\
\hline 33 & Miami & Plain chicken luncheon & + ve \\
\hline 34 & Miami & Chicken frankfurter & + ve \\
\hline $35 * *$ & Stanley & Chicken frankfurter & $-v e$ \\
\hline 36 & El Asafra & Chicken frankfurter & + ve \\
\hline 37 & Moustafa Kamel & Chicken frankfurter & + ve \\
\hline 38 & Sporting & Chicken frankfurter & + ve \\
\hline 39 & Kafr Abdo & Chicken frankfurter & + ve \\
\hline $40 *$ & El Seyouf & Nuggets & + ve \\
\hline
\end{tabular}

*Positive $R$. ornithinolytica on XLD. **The samples did not show any growth on XLD. $R$. ornithinolytica=Raoultella ornithinolytica

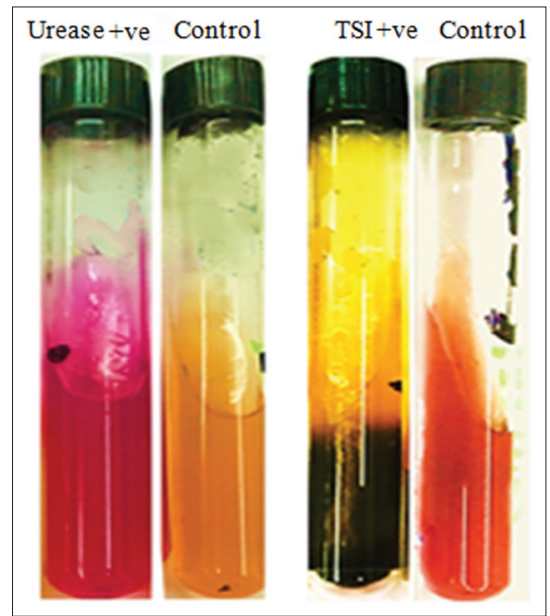

Figure-2: Identification of Raoultella ornithinolytica using Triple Sugar Iron Agar and urease test.

U.K, depicted in Figure-4) [20,21]. The samples were exposed to 15 discrete antibiotics (Table-2), the first sample demonstrated resistance to five types of antibiotic disks (FLX, ERY, P, AMC, and BAC), intermediate sensitivity was found to two antibiotics (AMX and AMP), and sensitivity to eight antibiotics (C, CS, NA, CIP, TE, OTC, AMK, and S). The second sample demonstrated resistance to 10 antibiotics (FLX, AMP, ERY, P, TE, OTC, AMC, AMX, S, and BAC). Intermediate sensitivity was found to only one antibiotic (NA) and sensitive to four antibiotics (C, CIP, CS, and AMK). The third sample demonstrated resistance to 10 antibiotics (FLX, AMP, ERY, P, tetracycline, OTC, AMC, AMX, S, and BAC). Intermediate sensitivity was found for two antibiotics (CIP and AMK) and sensitivity to three antibiotics (C, CS, and NA).

\section{Discussion}

In the past few decades, serious infections have occurred through emerging diseases. $R$. ornithinolytica infections were once rare in humans; however, 


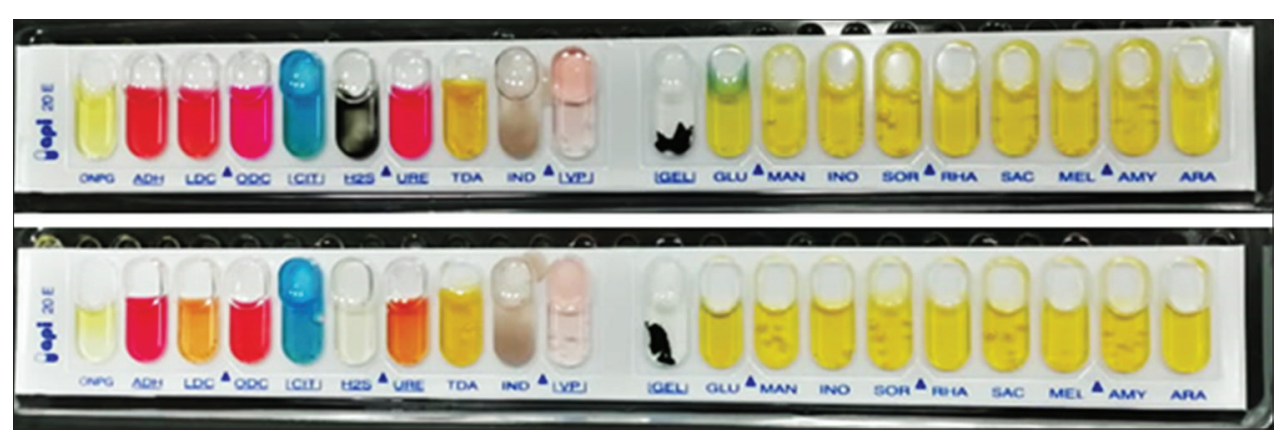

Figure-3: Identification of Raoultella ornithinolytica using phenotypic system API 20E for isolates no 28 and 40.

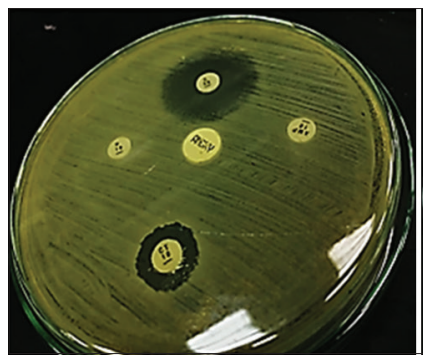

Figure-4: Mueller-Hinton agar media showing the susceptibility of 10 types of antibiotic against Raoultella ornithinolytica isolate (sample 40).

recently, this pathogen is emerging and is associated with foodborne illness [22], toxicity, septicemia, bacteremia, enteric fever, scombroid poisoning, and immune deficiency $[15,23-30]$. Furthermore, $R$. ornithinolytica is commonly misidentified in clinical microbiology laboratories, as this bacterium is quite similar to Klebsiella species [31]. Therefore, the correct identification of $R$. ornithinolytica is important for treating patients and improving the classification and characterization of this bacterial species. In the current study, three strains of $R$. ornithinolytica were isolated from chicken products (Figure-1), subjected to four manual laboratory biochemical tests, which included oxidase, TSI, LIA, and urease (Table-1). $R$. ornithinolytica was identified through the following morphological characters, biochemical reaction, growth temperature, and pigment production $[7,8,16]$. The first preliminary identification in this study was confused with Klebsiella oxytoca. Subsequent testing using the phenotype system API 20E (bioMérieux), identified these samples as $R$. ornithinolytica. API 20E (bioMérieux) is considered a discriminatory method which uses ornithine decarboxylase (ODC) tests to differentiate between $R$. ornithinolytica positive (ODC + ) and $K$. oxytoca negative (ODC-) [18]. The phenotype recognition results were confirmed through an emerging microbial diagnostic technology (MALDI-TOF MS).

Then, the samples were subjected to disk diffusion to determine their antibiotic profiles. However, there are many variables that could influence the outcome of the data interpreted through disk susceptibility determinations, such as similarity in minimum inhibitory concentration for the antibiotic disk accompanied by great variation in the sensitivity result within the same species. A possible explanation for this conflict might be attributed to the fact that the resistance of $R$. ornithinolytica to different types of antibiotics was not increased sufficiently or might be due to a higher microbial load as reported in our study, there were some differences found in the susceptibility ratio between the parents of isolated strains varying from 1:4. Furthermore, the presence of more than 1 isolate from the same sample, taken at different times, showed variability in the susceptibility profile overtime [32].

The results of this study were consistent with that of other recent studies denoting the efficacy and efficiency of MALDI-TOF MS for the identification of Gram-negative bacteria [13,33,34]. Moreover, this study indicated that a replacement for the traditional identification method for $R$. ornithinolytica isolation in the microbiology laboratory was important. Since this technology was simple, fast, and reliable, API 20E and MALDI-TOF MS should be considered for further studies. However, improvements would be required in sample preparation and the availability of databases specifically designed to identify significant strains.

\section{Conclusion}

This is the first study in Egypt that illustrates the isolation of the extremely rare pathogen $R$. ornithinolytica from the chicken products which demonstrated an excellent prognosis with antibiotic susceptibility, as reported in the literature.

\section{Authors' Contributions}

SME created the research and experimental design, performed the laboratory experiment, data analysis, and wrote the manuscript. AAAE supervised the experiment, checked the data analysis, and revised the manuscript. WMMH supervised the experiment, helped in the laboratory work, and revised the manuscript. All authors contributed to the drafting and revision of the manuscript. All authors read and approved the final manuscript.

\section{Acknowledgments}

The authors are thankful to Reference Laboratory for Quality Control on Poultry Production, Animal 
Health Research Institute, Dokki, Giza, Egypt, for providing the necessary laboratory facilities for this study. The author did not receive any funds for this research.

\section{Competing Interests} interests.

The authors declare that they have no competing

\section{Publisher's Note}

Veterinary World remains neutral with regard to jurisdictional claims in published institutional affiliation.

\section{References}

1. Drancourt, M., Bollet, C., Carta, A. and Rousselier, P. (2001) Phylogenetic analyses of Klebsiella species delineate Klebsiella and Raoultella gen. nov., with description of Raoultella ornithinolytica comb. nov., Raoultella terrigena comb. nov. and Raoultella planticola comb. nov. Int. J. Syst. Evol. Microbiol., 51(3): 925-932.

2. Ferragut, C., Izard, D., Gavini, F., Kersters, K., Ley, J.D. and Leclerc, H. (1983) Klebsiella trevisanii: A new species from water and soil. Int. J. Syst. Evol. Microbiol., 33(2): 133-142.

3. Park, J.S., Hong, K.H., Lee, H.J., Choi, S.H., Song, S.H., Song, K.H. and Kim, E.C. (2011) Evaluation of three phenotypic identification systems for clinical isolates of Raoultella ornithinolytica. J. Med. Microbiol., 60(4): 492-499.

4. Westbrook, G.L., O'Hara, C.M., Roman, S.B. and Miller, J.M. (2000) Incidence and identification of Klebsiella planticola in clinical isolates with emphasis on newborns. J. Clin. Microbiol., 38(4): 1495-1497.

5. Bjornsdottir-Butler, K., Bowers, J.C. and Benner, R.A. Jr. (2015) Prevalence and characterization of high histamine producing bacteria in Gulf of Mexico fish species. J. Food Prot., 78(7): 1335-1342.

6. Gajdács, M. (2020) Epidemiology of Raoultella species in the context of human infections: A 10-year retrospective study in a tertiary-care hospital in Hungary. Trends Med., 20(1): $1-4$

7. Gajdács, M., Ábrók, M., Lázár, A. and Burián, K. (2019) Comparative epidemiology and resistance trends of common urinary pathogens in a tertiary-care hospital: A 10-year surveillance study. Medicina, 55(7): 356.

8. Gajdács, M. and Urbán, E. (2019) Resistance trends and epidemiology of Citrobacter-Enterobacter-Serratia in urinary tract infections of inpatients and outpatients (RECESUTI): A 10-year survey. Medicina, 55(6): 285.

9. Bagley, S.T., Seidler, R.J. and Brenner, D.J.(1981) Klebsiella planticola sp. nov.: A new species of Enterobacteriaceae found primarily in nonclinical environments. Curr. Microbiol., 6(2): 105-109.

10. Izard, D., Ferragut, C., Gavini, F., Kersters, K., Ley, J.D. and Leclerc, H. (1981) Klebsiella terrigena, a new species from soil and water. Int. J. Syst. Evol. Microbiol., 31(2): 116-127.

11. Sakazaki, R., Tamura, K., Kosako, Y. and Yoshizaki, E. (1989) Klebsiella ornithinolytica sp. nov., formerly known as ornithine-positive Klebsiella oxytoca. Curr. Microbiol., 18(4): 201-206.

12. Mollet, C., Drancourt, M. and Raoult, D. (1997) rpoB sequence analysis as a novel basis for bacterial identification. Mol. Microbiol., 26(5): 1005-1011.

13. De Jong, E., Jong, A.S., Berg, N.S.V. and Rentenaar, R.J. (2013) Differentiation of Raoultella ornithinolytical planticola and Klebsiella oxytoca clinical isolates by matrix-assisted laser desorption/ionization-time of flight mass spectrometry. Diagn. Microbiol. Infect. Dis., 75(4): 431-433.

14. De Jong, E., Erkens-Hulshof, S., Velden, L.B., Voss, A., Bosboom, R., Hodiamont, C.J. and Sturm., P.D. (2014) Predominant association of Raoultella bacteremia with diseases of the biliary tract. Scand. J. Infect. Dis., 46(2): 141-143.

15. Kanki, M., Yoda, T., Tsukamoto, T. and Shibata, T. (2002) Klebsiella pneumoniae produces no histamine: Raoultella planticola and Raoultella ornithinolytica strains are histamine producers. Appl. Environ. Microbiol., 68(7): 3462-3466

16. McFaddin, J.F. (2000) Biochemical Tests for the Identification of Medical Bacteria. $3^{\text {rd }}$ ed. Lippincott Williams and Wilkins, Philadelphia, PA.

17. Gajdács, M. (2019) Epidemiology and antibiotic resistance trends of Pantoea species in a tertiary-care teaching hospital: A 12-year retrospective study. Dev. Health Sci., 2(3): 72-75.

18. Walckenaer, E., Poirel, L., Leflon-Guibout, V., Nordmann, P. and Nicolas-Chanoine, M.H. (2004) Genetic and biochemical characterization of the chromosomal class A $\beta$-lactamases of Raoultella (formerly Klebsiella) planticola and Raoultella ornithinolytica. Antimicrob. Agents Chemother., 84(1): 305-312.

19. Gajdács, M. and Urbán, E. (2019) The relevance of anaerobic bacteria in brain abscesses: A ten-year retrospective analysis (2008-2017). Infect. Dis., 51(10): 779-781.

20. Bauer, A., Kirby, W.M., Sherris, J.C. and Turck, M. (1966) Antibiotic susceptibility testing by a standardized single disk method. Am. J. Clin. Pathol., 45(4): 493-496.

21. Sala, A., Taddei, S., Santospirito, D., Sandri, C., Magnone, W. and Cabassi, C.S. (2016) Antibiotic resistance in conjunctival and enteric bacterial flora in raptors housed in a zoological garden. Vet. Med. Sci., 2(4): 239-245.

22. Seng, P., Boushab, B.M., Romain, F., Gouriet, F., Bruder, N., Martin, C. and Paganelli, F. (2016) Emerging role of Raoultella ornithinolytica in human infections: A series of cases and review of the literature. Int. J. Infect. Dis., 45: 65-71.

23. Mau, N. and Ross, L.A. (2010) Raoultella ornithinolytica bacteremia in an infant with visceral heterotaxy. Pediatr. Infect. Dis. J., 29(5): 477-478.

24. Hadano, Y., Tsukahara, M., Ito, K., Suzuki, J., Kawamura, I. and Kurai, H. (2012) Raoultella ornithinolytica bacteremia in cancer patients: Report of three cases. Int. Med., 51(22): 3193-3195.

25. Kaya, S.G. (2015) Raoultella ornithinolytica causing fatal sepsis. Braz. J. Infect. Dis., 19(2): 230-231.

26. Haruki, Y., Hagiya, H., Sakuma, A., Murase, T., Sugiyama, T. and Kondo, S. (2014) Clinical characteristics of Raoultella ornithinolytica bacteremia: A case series and literature review. J. Infect. Chemother., 20(9): 589-591.

27. Chun, S., Yun, J.W., Huh, H.J. and Lee, N.Y. (2015) Clinical characteristics of Raoultella ornithinolytica bacteremia. Infection, 43(1): 59-64.

28. Sekowska, A., Dylewska, K., Gospodarek, E. and Bogiel, T. (2015) Catheter-related blood stream infection caused by Raoultella ornithinolytica. Folia Microbiol., 60(6): 493-495.

29. Sueifan, M., Moog, V., Rau, E. and Eichenauer, T. (2016) Sepsis durch Raoultella ornithinolytica bei einem immunkompetenten patienten. Anaesthesist, 65(2): 129-133.

30. Boattini, M., Almeida, A., Cardoso, C., Cruz, C.S., Machado, C., Vesza, Z. and Moura, R. (2016) Infections on the rise: Raoultella spp., clinical and microbiological findings from a retrospective study, 2010-2014. Infect. Dis., 48(1): 87-91.

31. Hansen, D.S., Aucken, H.M., Abiola, T. and Podschun, R. (2004) Recommended test panel for differentiation of Klebsiella species on the basis of a trilateral interlaboratory evaluation of 18 biochemical tests. J. Clin. Microbiol., 
42(8): 3665-3669.

32. Waksman, S.A., Reilly, H.C. and Schatz, A. (1945) Strain specificity and production of antibiotic substances: V. Strain resistance of bacteria to antibiotic substances, especially to streptomycin. Proc. Natl. Acad. Sci. U. S. A., 31(6): 157-64.

33. Florio, W., Cappellini, S., Giordano, C., Vecchione, A., Ghelardi, E. and Lupetti, A. (2019) A new culture-based method for rapid identification of microorganisms in polymicrobial blood cultures by MALDI-TOF MS. BMC Microbiol., 19(1): 1-7.

34. Saffert, R.T., Cunningham, S.A., Ihde, S.M., Jobe, K.E., Mandrekar, J. and Patel, R. (2011) Comparison of Bruker biotyper matrix-assisted laser desorption ionization time of flight mass spectrometer to BD phoenix automated microbiology system for identification of gram-negative bacilli. $J$. Clin. Microbiol., 49(3): 887-892.

\section{$* * * * * * * *$}

